\title{
CAPÍTULO $_{4}$
}

\section{LA FAMILIA COMO COMUNIDAD DE FE Y ESPERANZA}

En el capítulo anterior nos acercamos a la familia como comunidad de vida y amor y analizábamos la fuerza y el contenido de esta expresión ya clásica en el Concilio y en los documentos principales sobre la familia, en los cuales se observa claramente que el amor constituye la esencia de la vida familiar. Un amor que no es vacío de significado, sino que encierra en sí mismo un caudal de actitudes y prácticas concretas que lo hacen ser verdadero como la fidelidad, la unidad, la exclusividad, la fecundidad, apertura a los demás, entre otras.

Sin embargo, para que la familia sea verdaderamente una comunidad de vida y amor debe estar cimentada en suelo firme, en la roca que la haga estar en pie frente a viento y marea. Este suelo y esa roca se llaman fe y esperanza, en otras palabras, la esperanza de la fe. De tal manera que sin fe y esperanza, el amor verdadero no tiene fuerza para subsistir y sin el amor verdadero tampoco la fe y la esperanza se sostienen.

Si en el anterior apartado nos referíamos a la crisis del amor y a una tergiversación del amor, en este capítulo veremos que la familia, para mostrar su esplendor y su verdad, está llamada a transmitir la esperanza y dar luz frente a un mundo desesperanzado, que sume a las personas en una profunda soledad y egoísmo. La familia, entonces, como comunidad de vida y amor, es también comunidad de fe y esperanza. Ella, peregrina en la esperanza y su aporte a la evangelización, lo hace precisamente bajo el signo de la esperanza cristiana ${ }^{ }$.

I Cf. EN 28. 


\section{Cuestiones en la sociedad actual que dificultan la función de la familia como comunidad de fe y esperanza}

Panorama general: un mundo bajo la sombra de la desesperanza

La voz del Concilio que alertaba sobre la situación desorientada del hombre moderno con el paso del tiempo se ha ido agudizando. El Concilio interpretó la metamorfosis del mundo actual y sus cambios, principalmente en lo social, como parte de un proceso en crecimiento, ${ }^{2}$ pero tales cambios se han instalado en la cultura con un peso casi inamovible. La sombra de la desesperanza se ha hecho más oscura y espesa; las tristezas y angustias de los hombres de nuestro tiempo parecen eclipsar sus gozos y esperanzas.

Las cuestiones sobre el avance de una sociedad industrial, científica y materialista no han ido de la mano del avance de una verdadera humanización del hombre, "se [ha] busca[do] intensamente un más perfecto orden de lo temporal, sin que progrese paralelamente el desarrollo espiritual"3.

Diversos autores coinciden, sin caer en el fatalismo, que una característica destacable de nuestro tiempo es la desesperanza. Desesperanza en el orden teórico y práctico que nos ha llevado a vivir en una época de desesperanza. Según Albert Nolan, la desesperanza es el estado de ánimo sentido más profundamente en nuestro tiempo, ya que durante siglos habíamos experimentado esperanza y optimismo de uno u otro tipo (político, económico, científico y religioso). Ahora, de pronto, con las esperanzas frustradas de los siglos pasados, casi todas las personas se encuentran sumidas en un estado de no esperar nada o casi nada 4 . No es que en este mundo no se encuentren esperanzas, las hay, pero sus sombras hacen brillar menos la luz de la esperanza.

Olegario González por su parte, explica que después de las dos guerras mundiales; después del hundimiento de los ideales conexos con el marxismo y del descrédito de todos los socialismos políticamente

\footnotetext{
Cf. GS 4 c.

GS 4 d.

Cf. Albert Nolan, Esperanza en una época de desesperanza, (Santander: Sal Terrae, 2010), I6.
} 
realizados tras él y conexos con él; después de la crisis de los tecnicismos y capitalismos; después de la sospecha contra todos los absolutos y entre ellos contra todos los monoteísmos, hoy estamos ante la sagrada tarea de "refundar la esperanza".

La crisis anterior, según Olegario González, no puede llevarnos al desencanto del mundo, a la renuncia a la gloria del hombre, a la desesperanza ante el futuro y propone este "refundar la esperanza" entendida como un repensar y reemprender el camino de la esperanza, preguntando por su fundamento antropológico, su posibilidad teológica y su concreción histórica 6 .

A lo anterior también contribuye que las pequeñas esperanzas que promociona la cultura, ayudada por los medios de comunicación social y sostenido por intereses económicos y políticos, crea una percepción del ser humano que lo sume aún más en la desesperanza. Jesús García Rojo lo interpreta de esta manera:

[...] en contra de lo que cabría sospechar, el hombre de la sociedad moderna no es más feliz ni ha orientado su vida mejor que el hombre de épocas pasadas. En realidad, vaciado de su interioridad, el hombre de la sociedad moderna se convierte en instrumento de trabajo y pieza de repuesto de una gran máquina que arroja dinero, pero quita las ganas de vivir. Por sí mismos, trabajo, éxito, dinero, no son sinónimos de sentido, ni son tampoco garantía segura de felicidad?

Con respecto a la familia, en los tiempos modernos, ha sufrido, quizá como ninguna otra institución, la acometida de las transformaciones amplias, profundas y rápidas de la sociedad y de la cultura ${ }^{8}$. El Concilio, ante los desequilibrios del mundo moderno, ya alertaba de las dificultades sobre la familia, debidas o a presiones de las condicio-

5 Cf. Olegario González de Cardedal, Raíz de la Esperanza, (Salamanca: Ediciones Sígueme, 1995), 48I.

6 Cf. Ibíd., 48I.

7 Jesús García Rojo, La pregunta por el sentido. Problemática filosófico-teológica actual, (Salamanca: Publicaciones Universidad Pontificia de Salamanca, I988), 6.

8 Véanse los trabajos del Congreso Internacional sobre la Familia, celebrado en Salamanca entre el i6 y el i8 de marzo de 1994, que giraban alrededor de la relación de la familia con la sociedad y la cultura, presentando un cuadro completo sobre la familia en el mundo actual, en: Dionisio Borobio (coord.), Familia en un mundo cambiante, (Salamanca: Publicaciones Universidad Pontificia de Salamanca, 1994). 
nes demográficas, económicas y sociales, las dificultades que surgen entre las sucesivas generaciones, o a las nuevas formas de relación social entre hombre y mujer 9 .

Concretamente el Concilio se refería a situaciones que eran y siguen siendo hoy motivo de desesperanza y reto para la familia cristiana, tales como la poligamia, el divorcio, el llamado amor libre y otras deformaciones análogas. El amor conyugal, pilar de la familia como comunidad de vida y amor, se ve profanado por el egoísmo, el hedonismo, el aborto, etc. También se mencionan las condiciones económicas, sociales, psicológicas y civiles que acarrean no leves perturbaciones a la familia. Por último, se hacían preocupantes, en determinadas partes del mundo, los problemas que surgían de la explosión demográfica ${ }^{\mathrm{IO}}$.

Hace casi dos decenios la FC ya presentaba su preocupación por la incertidumbre y desánimo que causaba en las familias la situación del mundo actual, refiriéndose concretamente a los signos de preocupante degradación de algunos valores fundamentales: una equivocada concepción teórica y práctica de la independencia de los cónyuges entre sí, las graves ambigüedades acerca de la relación de autoridad entre padres e hijos; las dificultades concretas que con frecuencia experimenta la familia en la transmisión de los valores; el recurso cada vez más frecuente de esterilizaciones, la instauración de una verdadera y propia mentalidad anticoncepcional ${ }^{\mathrm{II}}$.

Estas situaciones, según la FC, son signo del rechazo que el hombre opone al amor de Dios y, por consiguiente, nublan la esperanza cristiana. En la base de estos fenómenos negativos se encuentra, muchas veces, una corrupción de la idea y de la experiencia de la libertad, concebida no como la capacidad de realizar la verdad del proyecto de Dios sobre el matrimonio y la familia, sino como una fuerza autónoma de autoafirmación, no raramente contra los demás, sobre el propio bienestar egoísta ${ }^{12}$.

Cf. GS 8c.

Io $\mathrm{Cf}$. GS $47 \mathrm{~b}$.

II Cf. FC 6b.

I2 Cf. FC 6c. 
Si lo hasta ahora dicho son signos de desesperanza, la Iglesia propone iluminar las sombras que se ciernen sobre el mundo y especialmente a la familia, a través de la educación en el amor enraizada en la fe y la esperanza ${ }^{13}$. La Iglesia está convencida de que tanto ayer como hoy debe seguir anunciando la fe en Cristo muerto y resucitado por todos $^{14}$, ya que Él ofrece al hombre, por medio de su Espíritu, luz y fuerzas que le permitan responder a su altísima vocación. En Él se encuentra la clave, el centro y el fin de toda la historia humana. Bajo la superficie de lo cambiante, hay muchas cosas permanentes que tienen su fundamento último en Él' ${ }^{15}$. La Iglesia sostiene que Cristo es su esperanza en su peregrinar por el mundo entre "el gozo y la esperanza, las tristezas y angustias de nuestros días"16 con la firme confianza de que prevalecerá el bien sobre el mal, el gozo sobre la tristeza, la esperanza sobre la desesperanza.

La familia como comunidad de fe y esperanza encuentra en este mundo falto de esperanza un reto importante: mostrarle que su amor conyugal y fraterno está anclado en una fe y una esperanza que no defrauda, que salta para la vida eterna, conscientes de que la "la puerta es estrecha y angosta la senda que lleva a la vida' (Mt 7:I4). La esperanza de esta vida debe iluminar su camino, mientras se esfuerzan [los cónyuges cristianos] animosamente por vivir con prudencia, justicia y piedad el tiempo presente (Tt 2:I2), conscientes de que la forma de este mundo es pasajera (I Co 7:3I)"17.

\section{El ser humano entre la profunda soledad y el egoísmo}

La crisis de la esperanza en el mundo actual conlleva la crisis en el ser humano concreto que se percibe sin esperanza, sin sentido, con un horizonte cerrado de posibilidades. Se ha caído en una existencia nihilista y egoísta que recorta la esperanza y se rodea de la nada.

13 Cf. FC 6f.

14 Cf. 2 Cor 5, I5.

I5 Cf. GSiob.

I6 GS I.

I7 HV 25c. 
Leonardo Polo $^{18}$ acertadamente traduce las respuestas que darían la mayoría de los hombres y que hablan de este "esperar poco":

- ¿Quién te ha encargado la tarea de existir? Nadie.

- ¿Con qué ayudas cuentas? Solo con mis propios recursos.

- ¿Quién es tu adversario? Todos los demás.

- ¿Quién es el beneficiario? Solamente yo.

Las anteriores respuestas son un ejemplo claro de la percepción de la vida como azar, individualista, en la que al ser humano no se le ha encargado la tarea de existir y realizarse con los demás, junto a los demás, sin más beneficiario que el sujeto mismo. Lo lamentable es que hemos sucumbido a este engaño y con él se ha herido al hombre mismo que es un ser de esperanza. El hombre lanzado a vivir en un presente con un futuro incierto vive con la angustia de gozar plenamente el momento actual.

Llama la atención de que el progreso científico-técnico del que goza la cultura actual haya creado una angustia cada vez más profunda ante el futuro y haya frustrado las esperanzas de una humanidad nueva y mejor. El rechazo hacia la vida naciente, según la FC, es un ejemplo claro de hasta dónde ha llegado la desesperanza en el futuro de la humanidad. La FC $30 b$ lo describe así:

Algunos se preguntan si es un bien vivir o si sería mejor no haber nacido; dudan de si es lícito llamar a otros a la vida, los cuales quizás maldecirían su existencia en un mundo cruel, cuyos terrores no son ni siquiera previsibles. Otros piensan que son los únicos destinatarios de las ventajas de la técnica y excluyen a los demás, a los cuales imponen medios anticonceptivos o métodos aún peores. Otros todavía, cautivos como son de la mentalidad consumista y con la única preocupación de un continuo aumento de bienes materiales, acaban por no comprender, y por consiguiente rechazar la riqueza espiritual de una nueva vida humana. 
La misma exhortación concluye que la razón última de estas mentalidades es la ausencia, en el corazón de los hombres, de Dios, de su amor y esperanza que desvanece con su fuerza todos los posibles miedos y los puede vencer y proclama que contra el pesimismo y el egoísmo, que ofuscan el mundo, la Iglesia está a favor de la vida, porque anuncia al Dios de la esperanza ${ }^{19}$.

Y es en relación a la vida humana en donde se encuentra el signo más visible de la pérdida de la esperanza actual, constatándose una crisis del sentido de lo humano. Nuestro tiempo marcado por la crisis (política, cultural, religiosa, económica, educativa y social) ha pensado que la crisis es externa, de instituciones, cuando la raíz de la crisis está en la base de la realidad: el ser humano, que configura las demás realidades. Nunca como hoy hemos asistimos a una profunda crisis de sentido de lo humano. "Crisis de sentido ha habido siempre. Pero, tal vez, nunca como hoy la crisis de sentido adquirió dimensiones tan amplias y tonos tan dramáticos. No es extraño, entonces, que al referirse a ella, los autores hablen de 'profunda crisis de sentido"'20.

Se percibe en el hombre de hoy en relación con la vida, parafraseando a Pierre Teilhard de Chardin, una falta de gusto por la existencia, por el gozo de ser humanos. La visión negativa y pesimista del mundo recorre los rincones de nuestra sociedad. Es evidente, además, que en esta crisis hay, en sentido negativo, personas que viven sin querer vivir y llenan el mundo de nostalgia y pesimismo, o viven la vida haciendo violencia contra ella. La maldad del mundo está en relación con la idea que se tiene del ser humano, o dicho positivamente: "el bien de la persona, está ligado a la 'idea' que se tenga del hombre, de la persona humana"21.

El ser humano desprovisto de sentido, de significado, produce un sinsentido (la nada), vivir sin el gusto de vivir sería lo más normal del hombre de hoy, aunque no lo exprese abiertamente, pero sus hechos sí que lo demuestran; hasta el pensamiento lo hemos convertido en

I9 Cf. FC 3ob.d.

20 Jesús García Rojo, La pregunta por el sentido. Problemática filosófico-teológica actual..., 5.

2I Cf. El estudio que hace el profesor Sarmiento sobre los tipos de ética que prevalecen en la cultura actual sobre la persona humana. Augusto Sarmiento, "El servicio de la teología moral a la bioética", Scripta Theologica 40 (2008) $777-800$. 
nada, vacío de argumentos. La nombrada posmodernidad ${ }^{22}$ llama al pensamiento "débil" que surge precisamente como síntoma de la cultura actual en crisis, un pensamiento que no sostiene la existencia, que produce el no saber a dónde ir, ni qué esperar, es decir, sin sentido.

En la sociedad actual el ser humano percibe su valor no en sí mismo, sino en las cosas externas a él. Esta mirada de la realidad le ha llevado a valorar más los animales, el dinero, la tecnología, que a sí mismo. Lo que da valor a su vida es una apropiación consciente de valores, actitudes, objetos que lo hacen valer más; por lo tanto, quien no posee esos valores que la sociedad ha marcado como "buenos" no vale o no es digno de vivir. El problema radica en que el ideal antropológico, tal como está, es inalcanzable o genera, en su consecución, violencia contra sí mismo y contra los demás.

Ante tal visión, no es extraño entonces que los niveles de soledad y egoísmo le resulten alarmantes a la misma sociedad. Precisamente la declaración de Río de Janeiro sobre la familia del año 997 prevenía sobre el daño que la mentalidad individualista y egoísta causaba a la sociedad y a la familia. Concretamente hablaba este documento sobre las tendencias materialistas de la sociedad actual y la aceptación social del egoísmo y la irresponsabilidad que disgrega de la familia y propone redescubrir el sentido de la comunidad conyugal mediante la integración de la sexualidad humana en una entrega seria, responsable y total a la vida.

Ante el cuadro anterior, el mismo documento en clave de esperanza se proponía con confianza proclamar la verdad de la familia, el evangelio de la familia, que se revela cuando se le considera como don, compromiso y esperanza para la humanidad. La familia está llamada a ser la comunidad en la que la fe y la esperanza brillen. Ella, como comunidad de amor, fe y esperanza, puede dar luz a este

22 Véase el estudio que hace Bruno Forte sobre el mundo actual en relación con sus esperanzas frustradas. Este autor expresa que la mayor enfermedad de hoy es la falta de pasión por la verdad producto de la crisis de la época actual cuyo rostro es de decadencia: decadencia que no es el abandono de los valores, ni la renuncia a vivir por algo por lo que, de todos modos, se considera que merece la pena vivir. La decadencia es el proceso mucho más sutil que priva al hombre de la pasión por la verdad, quitándole el ansia de combatir por una razón más alta. En el clima de la decadencia todo conspira para que el hombre ya no piense más, huya de la fatiga por la pasión por la verdad, y se abandone al placer inmediato, calculable con el solo interés del consumo inmediato. Cf. Bruno Forte, "Cristo, "nuestra esperanza', revela el sentido de la vida y de la historia", Scripta Theologica 33 (2001/3), 829. 
mundo desesperanzado sumido en la soledad y el egoísmo, brindarle la alegría y la esperanza de Cristo. No sin razón el papa Juan Pablo II en el Primer encuentro mundial de las familias, celebrado en Roma en 1994, insistió: “Familias, ¡Sed gaudium et spes, alegría y esperanza!"

\section{La comprensión de la familia como comunidad de fe y esperanza}

Ante el panorama anterior que hemos descrito de un mundo desesperanzado que lanza al hombre a una profunda soledad y egoísmo y sus repercusiones en la familia, ésta vuelve su mirada al único que puede llenarla de fe y esperanza no solo en el futuro, sino en el propio presente. Si el magisterio ha insistido en que la familia es la esperanza y el futuro de la humanidad ${ }^{23}$, esto solo es posible si ella misma bebe de la fuente de la esperanza que es Cristo, si ella misma está anclada en la "fe en Cristo" y si el amor con el que ama es el de Cristo.

El magisterio sobre la familia sostiene la convicción anterior de manera arraigada: ¡Cristo es la esperanza de las familias! El número I3d de la FC para hablar de la grandeza y belleza de la vida conyugal en Cristo, citando a Tertuliano ${ }^{24}$, se refiere a que esta vida conyugal en Cristo es posible si ellos están unidos en una sola esperanza y podríamos decir también en una fe y en un único amor. "La esperanza y la fe son la fuerza que sostienen a la familia comunidad de amor" 25.

Ser una sola carne es más que vivir juntos para siempre, significa unidad en una sola esperanza, un solo propósito, una sola observancia, en una sola servidumbre, en un solo servicio. Eso es, haciendo alusión a Tertuliano, a lo que apuntamos al hablar en este capítulo de la familia como comunidad de fe y esperanza: acentuamos la relación existente entre la familia y Cristo y la vivencia del amor, la fe y la esperanza en Cristo en el seno familiar.

\footnotetext{
23 FC 86.

24 La cita completa de Tertuliano es la siguiente: “Cómo lograré exponer la felicidad de ese matrimonio que la Iglesia favorece, que la ofrenda eucarística refuerza, que la bendición sella, que los ángeles anuncian y que el Padre ratifica? [...] ¡Qué yugo el de los dos fieles unidos en una sola esperanza, en un solo propósito, en una sola observancia, en una sola servidumbre! Ambos son hermanos y los dos sirven juntos; no hay división ni en la carne ni en el espíritu. $\mathrm{Al}$ contrario, son verdaderamente dos en una sola carne y donde la carne es única, único es el espíritu". Tertuliano, Ad uxorem, II, VIII, 6-8: CCL I, 393.

25 Cf. FC 2of.
} 
Sobre esta interrelación de las virtudes teologales y su concreción en la vida cristiana familiar, el número $48 \mathrm{~b}$ de la FC lo aborda de manera explícita. Ese número explica que la "energía interior" de las familias cristianas lo constituyen su enraizamiento en la fe, esperanza y su vivificación por la caridad. Tal energía origina, difunde y desarrolla la justicia, la reconciliación, la fraternidad y la paz entre los hombres. Llama la atención que es precisamente en lo anterior en lo que la familia como "pequeña Iglesia", Iglesia doméstica, a semejanza de la "gran familia", encuentra su misión: en "ser signo de unidad para el mundo y ejercer su función profética, dando testimonio del Reino y de la paz de Cristo, hacia el cual el mundo entero está en camino"26.

Es decir, la familia, Iglesia doméstica, es lugar de profecía si su esperanza y su fe se transparentan en su caridad práctica, si su caridad — como acertadamente lo expresó Bruno Forte-, "es no sólo compartir la libertad que ama o la cruz que paga en persona por este amor, sino también el anuncio gozoso y radiante de un horizonte de esperanza que dé motivos ante la fatiga de vivir" 27 .

El mundo está ayuno de lugares que reflejen la alegría de vivir, el gozo de despertar cada mañana, de la experiencia auténtica del amor, de motivos para amar, esperar y confiar. Nunca como en estos tiempos a la Iglesia le urge presentar la esperanza en Cristo como la Buena Noticia que Jesús regala a la humanidad. Ante las durezas de la vida, ante las oscuridades y el pasajero eclipse de Dios y de la verdad sobre el hombre y sobre todo lo esencial para él, la familia puede ser una fuente magnífica de esperanza si ella misma se convierte en maestra de esperanza, en manantial de calma del dolor y del sufrimiento. En luz y fortaleza ante el desencanto del mundo; en día, aun cuando ciernen las tinieblas de la noche.

Para una profundización de la familia como comunidad de fe y esperanza presentaremos primero qué es lo propio de la esperanza cristiana, ya que, como vimos con el amor, es una palabra que necesita que se vuelva a resituar en su significado profundo. Después nos referiremos a dos puntos principales sobre la familia comprendida como 
el lugar privilegiado de peregrinación bajo la luz de la esperanza y, a la vez, portadora en este peregrinaje de un sentido sobre el hombre, sobre Dios, sobre la verdad de la realidad que ella está invitada a proclamar contra viento y marea. Luego haremos un análisis de la esperanza en la encíclica Spe salvi de Benedicto XVI y culminaremos en el rostro de la familia como escuela de amantes, creyentes y "esperantes".

\section{Las máscaras de la esperanza cristiana}

La familia comprendida como comunidad de fe y esperanza se ubica en el corazón mismo de la esperanza cristiana ¿Cuál es ese corazón?, ¿qué es lo fundamental de la esperanza de la fe y de la fe que suscita esperanza y amor? Para responder a estos interrogantes primero hay que profundizar en las comprensiones superficiales que desvirtúan el sentido original de la esperanza, rostros equivocados de la esperanza en los que las personas ponen su confianza y dirigen sus acciones.

Para que brille la esperanza cristiana, su novedad y la urgencia de que la familia sea consciente de su papel en sí misma, de la Iglesia y de la sociedad como comunidad de fe y esperanza, debemos profundizar en las sombras que oscurecen la comprensión de la verdadera esperanza.

El primer rostro tiene que ver con la no esperanza. Su devaluación se encuentra en el olvido de la dimensión del hombre como un ser esperanzado, creador de mundos posibles. El hombre traiciona ese ser esperanzador al concebir y decidir la existencia de un mundo sin Dios y de un hombre sin prójimo, siendo ésta la raíz profunda de la soledad moderna y su posterior estado desesperanzador, cuyo máximo exponente es Nietzsche. De este mundo sin Dios y de este mundo sin prójimo se deduce una realidad sin origen (verdad) y una historia sin destino (esperanza) ${ }^{28}$.

$\mathrm{Al}$ no existir un fundamento del mundo y una patria que espere al hombre para acogerle definitivamente, el hombre tiene que asumir el mundo sobre sus espaldas, otorgándole sentido y finalidad. Tal 
tarea sobrehumana al hombre le proporciona dignidad y orgullo en un primer instante, pesadumbre y angustia en el segundo ${ }^{29}$.

Esta no contemplación de la esperanza en el mundo y su ausencia se relaciona con la crisis de lo humano que antes hemos mencionado, en el sentido de que para dar el paso a la esperanza cristiana se necesita el componente antropológico básico de una esperanza inscrita en el ser del hombre que se comprende como un ser utópico ${ }^{30}$, de proyectos a realizar, de pequeñas esperanzas a concretar, de las ansias de felicidad que hay en el corazón humano.

Otro rostro equivocado de la esperanza tiene que ver con concebirla presente en el mundo pero en términos únicamente históricos, equiparándola más o menos a un optimismo basado en el presente, pero ajeno a la esperanza en el futuro. Es la paradoja de un optimismo pesimista fundado en el pensamiento de Leibniz, que afirma que este mundo es el mejor de los posibles, por eso hay que gozarlo en el momento presente, pero a la vez, el futuro es incierto, porque este mundo tal como está no es posible mejorarlo ${ }^{31}$.

La entraña de la esperanza es ajena a las dos concepciones anteriores, pero aún la esperanza cristiana corre el riesgo también de desvirtuarse mediante dos posturas presentes en la historia. La primera hace referencia a entender la esperanza en sentido exclusivamente sobrenatural bajo el lema de "Dios lo arreglará todo" escondiéndose en un pasivismo ante la realidad y una resignación que está lejos de ser cristiana. "No es infrecuente [en los cristianos] esta forma de catastrofismo derrotista sobre la situación de este mundo, combinada

\footnotetext{
29 Ibíd., 85.

30 Que el hombre sea un ser utópico significa que en él está la capacidad de trascender la realidad, el mundo físico, ir más allá de sus límites, problemas, condicionamientos. Lo admirable del hombre, dice Ernesto Sábato, es que siga luchando y creando belleza en medio de un mundo bárbaro y hostil. Esta capacidad de trascendencia, la capacidad de salir de sí y de sus propios límites, está reflejada en el impulso histórico del hombre de ir más lejos, de no dejarse encerrar, de proyectarse y buscar continuamente el sentido. En la perspectiva de Heidegger, el hombre es el único capaz de superar la inmanencia de la realidad mundana; y la supera siendo él mismo un proyecto, algo por hacer, por realizar. Cf. Gerardo Martínez, “Aportes para la comprensión de la historia de la Edad Media desde el horizonte de la utopía social cristiana”, Cuadernos de Filosofía Latinoamericana 93 (Bogotá, 2005), IOI.

3I Cf. Leonardo Polo, "La Esperanza", Scripta Theologica 30..., I57-I64, p. 157.
} 
con una forma de fideísmo irresponsable en un Dios mágico que ha de intervenir sobrenaturalmente para arreglarlo todo"32.

Si la anterior postura desvirtúa la esperanza por exceso de confianza en Dios sin participación humana, la siguiente postura peca por defecto porque centra la esperanza en los proyectos humanos; de tal manera que si fracasan éstos, fracasa también la esperanza, convirtiéndose en soporte ideológico de cualquier proyecto reformador o revolucionario. El lema es "el hombre lo arreglará todo porque cuenta con la ayuda de Dios". Se identifican proyectos humanos con proyectos divinos. "Esta clase de voluntarismo teñido de mesiánico puede ser peligroso. No hay nada más temible que un hombre o un grupo de hombres, que se sienten instrumentos de la justicia divina [...] corrompiendo la imagen del Dios de la misericordia"33.

\section{En el corazón de la esperanza cristiana}

Durante mucho tiempo, la teología de la esperanza estuvo anclada en un tratado de escatología que se entendía a sí mismo como la doctrina de "las últimas cosas" (de novissimis) -que abarcaba los temas de la muerte y el juicio, del cielo y el infierno- repercutiendo en una visión de la esperanza ubicada fuera de la historia ${ }^{34}$, siendo recurrentes los textos bíblicos de Eclo 7:40 y Mt I2:45 para sostener tal visión ${ }^{35}$.

La nueva visión de la escatología, y por lo tanto también de la esperanza, ha tenido como precursores a los teólogos protestantes Weiss, Schweitzer, Barth, Bultmann, Cullmann, Dodd, Moltmann y Pannenberg que, desde diversos aportes, rescataron la escatología y la ubicaron en su verdadero puesto en el cristianismo. En el ámbito católico, es digna de mencionar la influencia de los trabajos de Rahner, von Balthasar, Alfaro, Pieper, Wiederkehr, Nisbet, Laín Entralgo y González de Cardedal.

32 Josep Vives, "Esperanza cristiana y compromiso liberador", Sal Terrae 6 (I987) 457-467, p. 458.

33 Cf. Ibíd., 457-467, p.459.

34 Cf. Gerhard Ludwig. Müller, Dogmática: Teoría y práctica de la teología, (Barcelona: Herder, I998), $52 \mathrm{I}$.

35 "En todas tus acciones ten presente tu fin, y así jamás cometerás pecado" (Eclo 7,40). "Entonces va [el espíritu inmundo] y toma consigo otros siete espíritus peores que él; entran y se instalan allí, y el final de aquel hombre viene a ser peor que el principio. Así le sucederá también a esta generación malvada" (Mt I2,45). 
Sin hacer a un recorrido exhaustivo sobre este cambio, es digno de mencionar el aporte de Moltmann, quien marcó un camino decisivo en la reflexión sobre la esperanza, al relacionar la escatología directamente con la esperanza cristiana:

La escatología significa doctrina acerca de la esperanza cristiana, la cual abarca lo esperado como el mismo esperar vivificado por ello. En su integridad, y no sólo en su apéndice, el cristianismo es escatología; es esperanza, mirada y orientación hacia delante, y es también, por ello mismo, apertura y transformación del presente. Lo escatológico no es algo situado al lado del cristianismo, sino que es sencillamente, el centro de la fe cristiana, el tono con el que armoniza todo en ella, el color de aurora de un nuevo día esperado, color en el que aquí abajo está bañado todo ${ }^{36}$.

Para Moltmann la esperanza tiene como característica, a lo largo de la revelación, ser una esperanza activa e inquietante del hombre, que acontece en la historia, que no es estéril, sino que Dios mismo alimenta esa esperanza aconteciendo permanentemente en el ser humano. Una esperanza cuyas promesas se cumplen en la historia, pero con un movimiento de apertura, "un todavía no", un cumplimiento abierto al futuro.

Moltmann llega a la conclusión de que la Biblia es toda ella esperanza, "tanto en el Antiguo Testamento, como en el Nuevo, el fundamento de la esperanza siempre fue la seguridad de los creyentes en la fidelidad de Yahveh a las promesas hechas a Abraham y su descendencia y en el poder salvador del Resucitado por su Espíritu"37. La historia de la promesa llega a su culmen en Jesucristo en el acontecimiento de su muerte y resurrección ${ }^{38}$.

La esperanza se identifica con el anuncio de la promesa realizada en Jesucristo ${ }^{39}$. No es una esperanza que se deduzca de un concepto de Dios, sino que se apoya en las acciones de Dios en la historia, en

\footnotetext{
36 Cf. Jürgen Moltmann, Teología de la Esperanza..., 20.

37 Ibíd., 224.

38 Ibíd., I82.

39 Cf. Rom I5, I7; Is II, IO; Mt I2, 2 I.
} 
la persona y en las obras de Jesucristo, especialmente en su muerte y resurrección: comienzo de una nueva época ${ }^{40}$; justificación y reconciliación ${ }^{41}$; salvación acontecida en Cristo $^{42}$; don escatológico de salvación ${ }^{43}$.

Camilo Maccise, comentando el pensamiento de Moltmann, dirá acertadamente que éste, al hacer de la esperanza su principio teológico por excelencia, descubre el vacío de esperanza en la teología, ya que el cristianismo por haber predicado una fe sin esperanza, como compromiso en la transformación del mundo, contemplaba el surgimiento de muchas esperanzas sin fe en la época moderna ${ }^{44}$.

En el discurso teológico actual hay más claridad sobre la esperanza escatológica previniendo de reducir la escatología a una eventual doctrina de las ultimidades, del final de la historia y del mundo, anunciando un cataclismo cósmico que pondría fin al mundo visible o el de suplantar el futuro absoluto por un futuro intramundano propio del optimismo racionalista del siglo XVIII y de su fe ciega en el progreso ${ }^{45}$.

Sigo el pensamiento de Ruiz de la Peña, quien explica que la escatología es la reflexión creyente sobre el futuro de la promesa aguardado por la esperanza cristiana, el mismo hombre, en su constitución ontológica, es un ser proyectado constantemente hacia los límites de su presente: un hombre anclado en el presente, cumplidor del lema epicúreo del carpe diem, es un irresponsable; un hombre vuelto al pasado se convierte, como la mujer de Lot en estatua, se cosifica y despersonaliza. La índole personal y responsable del hombre sólo puede ser mantenida en la apertura al futuro ${ }^{46}$.

La pregunta en torno al futuro se hace acuciante para el ser humano, si quiere dar sentido a su existencia actual. Sin un cierto saber acerca del futuro, el presente carece de sentido y este saber es para

\footnotetext{
40 Cf. I Cor I5, 20; I Pe I, 3.

4I Rom 5,8-IO.

42 Rom 8,15.24.

432 Cor 3,4-I8. Cf. Mario Gutiérrez, "La Esperanza que compromete en la Historia", Theologica Xaveriana 48 (I998), 298.

44 Cf. Camilo Maccise, "Razones para testimoniar la esperanza en medio de la crisis”, en: Dar razón de la esperanza hoy, XXI Semana de Estudios de Teología pastoral, (Navarra: Verbo Divino, 2010), 232.

45 Cf. Juan Luis Ruiz de la Peña, La otra dimensión. Escatología cristiana, (Santander: Sal Terrae, 1986, 3 ed.), $30-33$.

46 Cf. Ibíd., 28.
} 
interpretar no el más allá sino su "más acá" 47 . Ruiz de la Peña coincide con Moltmann al afirmar que la escatología no habla de un futuro general, sino que arranca de una determinada realidad histórica y enuncia el futuro de ésta; la escatología cristiana habla de Jesucristo y del futuro en él ${ }^{48}$.

Recordando a Balthasar, que se refería a la escatología como una "cristología desarrollada", es posible afirmar que cuanto pueda decirse sobre el futuro absoluto desde la esperanza está prefigurado en el acontecimiento central de la historia que es Jesucristo. Él es, en verdad, como dice san Pablo, "nuestra esperanza". Y ello por partida doble: es el fundamento de nuestra esperanza y, simultáneamente, el contenido de la misma, puesto que es el lugar donde todas las promesas de Dios han tenido su sí y su amén ${ }^{49}$.

Hoy asistimos a la actualidad de la esperanza, a la reivindicación de la esperanza en la vida cristiana $^{50}$; una vida configurada desde Cristo "nuestra esperanza". Según Flecha, durante un tiempo la esperanza pasó casi inadvertida para la teología, que casi se limitaba a reflexionar sobre ella en el ámbito de las obras llamadas de la espiritualidad y pone de manifiesto la reivindicación de la esperanza por parte del marxismo con Ernst Bloch y, en el ámbito católico, el énfasis que recibió la esperanza escatológica en el Concilio ${ }^{51}$.

El Concilio ${ }^{52}$ en la constitución dogmática sobre la Iglesia presenta la centralidad de la esperanza cristiana y se refiere a la Iglesia como

47 Según Ruiz de la Peña, ante la acusación de evasión de la realidad y de desinterés por la historia y su presente, el cristianismo redescubre su componente escatológico y transformador de la realidad: "no necesitamos llegar al término absoluto del tiempo para descubrir el significado de la historia, puesto que éste se nos revela, de una vez por todas, en el suceso único que es Cristo, su vida y su pascua”. Vivir en Cristo y desde Cristo en el presente es preanunciar la vida futura y es a la vez transformar el mundo en la imagen de lo que será definitivamente. Cf. Ruiz de la Peña, La otra dimensión..., II2.

48 Cf. Ibíd., 28-29.

49 Cf. Ibíd., 30.

50 Según Maccise, la desvalorización de la esperanza tiene que ver también con el alejamiento de la Palabra de Dios que se vivió en la teología prácticamente hasta poco antes del Vaticano II. La esperanza se fue reduciendo a una actitud de espera paciente y resignada de la irrupción de lo definitivo en la historia humana, quedando relegada a un segundo plano frente a la fe y al amor. El regreso a la Escritura hizo que la esperanza ocupara el lugar que le corresponde en la teología y en la vida de los creyentes en Jesús y cita la famosa frase de Péguy, que manifiesta la renovada importancia que ha adquirido la esperanza en el cristianismo, "La fe que yo prefiero, dice Dios, es la esperanza". Cf. Maccise, "Razones para testimoniar la esperanza en medio de la crisis...", 23I. Cf. Flecha, Vida cristiana, vida teologal... I05.

52 Véase el estudio que hace Alfaro sobre el tratamiento que da el Concilio a la esperanza y su énfasis en el compromiso que con la vida cristiana y con la sociedad. Cf. Juan Alfaro, Esperanza cristiana y liberación del hombre, (Salamanca 
una comunidad de fe, esperanza y caridad ${ }^{53}$, a la vez anima al pueblo de Dios a dar testimonio de Cristo y a dar razón de su esperanza ${ }^{54}$, a ser testimonio de la esperanza cristiana5", por ser "hijos de la promesa" $^{56}$, peregrinos en la esperanza ${ }^{57}$.

Por su parte GS concreta el talante esperanzador de la Iglesia en el mundo siendo una comunidad que es solidaria con las esperanzas de todos los hombres y mujeres de la tierra, así como de sus preguntas e inquietudes, reconociendo al ser humano como un ser de esperanza ${ }^{58}$ y proclamando que Dios está presente en el mundo reavivando la esperanza. Esperanza que nace de la historia y de la Pascua del Señor y se orienta hacia la espera de su venida, ya que Cristo, hombre nuevo, trae los cielos nuevos y la tierra nueva ${ }^{59}$, invitando a los cristianos a dar testimonio activo de la esperanza por medio de su vida y el ejercicio de una caridad activa ${ }^{60}$.

El CCE I042-IO60 por su parte recoge las dos perspectivas de la esperanza. Se explica la esperanza en su dimensión escatológica y en su dimensión de sentido histórico. En esos números se explica que, precisamente, se vive en esperanza porque creemos en la vida eterna y a la inversa porque creemos en la vida eterna. El cristiano vive en esperanza, tiene sus ojos puestos en la vida futura sin descuidar la presente, en donde se juega su ser esperanzador. De allí que el número I049, citando a GS 39, I es fundamental para la comprensión de la esperanza: "No obstante, la espera de la tierra nueva no debe debilitar, sino más bien avivar la preocupación de cultivar esta tierra, donde crece aquel cuerpo de la familia humana, que puede ofrecer ya un cierto esbozo del siglo nuevo. Por ello hay que distinguir cuidadosamente el progreso terreno del crecimiento del Reino de Cristo [...]".

1972). Id., "Reflexiones sobre la Escatología del Vaticano II, en: Latourelle (ed.), Vaticano II: Balance y perspectivas (1962-1987)..., 789-797.

53 Cf. LG 8.

54 Cf. LG io.

55 Cf. LG 3I.

56 Cf. LG 35.

57 Cf. LG 48.

58 Cf. GS I.

59 Cf. GS 39.

6o Cf. GS 2I. Cf. Ibíd., I2I-I23. 
En la tercera parte del CCE dedicado a la vida en Cristo hay una intuición central para nuestro estudio. El signo del estar enraizados en Cristo, incorporados en él, siguiéndolo y uniéndonos a él, conformando nuestros pensamientos, palabras y acciones a las de él, tener sus sentimientos se realiza en la vivencia de la fe, la esperanza y la caridad que provienen de la Trinidad santa, "las virtudes teologales se refieren directamente a Dios. Disponen a los cristianos a vivir en relación con la Santísima Trinidad. Tiene como origen, motivo y objeto a Dios Uno y Trino" ". Las llamadas virtudes teologales hechas virtudes humanas ${ }^{62}$, fundan, animan y caracterizan el obrar moral del cristiano. Informan y vivifican todas las virtudes morales ${ }^{63}$.

Esta relación de la vivencia de las virtudes teologales en la vida cristiana se puede expresar de esta forma: la manera concreta de vivir la semejanza divina es configurar la existencia cristiana desde la fe, la esperanza y el amor, porque Dios mismo es fe, esperanza y amor, no en el sentido de que Dios ame, crea y espere como lo hacemos los seres humanos, sino en el sentido de que Él es el fundamento de nuestro amor, fe y esperanza. La vida de Cristo es el reflejo de esta vivencia divina al interior de la Trinidad Santa.

Pablo comprendió bien la anterior relación al definir a los discípulos de Cristo como los hombres y mujeres que viven en fe, caridad y esperanza ${ }^{64}$. Es decir, el signo de identidad del verdadero discípulo es la vivencia de su confianza absoluta en Dios, transmitiendo un estar en el mundo marcado por la esperanza y el amor. "La fe sin obras está muerta' (St 2:26), privada de la esperanza y de la caridad, la fe no une plenamente con Cristo ni hace de él un miembro vivo de su Cuerpo"65. Una fe con caridad pero sin esperanza es débil, su coraza es penetrable sino está revestida por el yelmo de la esperanza de la salvación ${ }^{66}$.

Desde lo anterior, queda claro que la esperanza no es la pariente pobre dentro de las virtudes teologales. Ella moviliza a sus hermanas

\footnotetext{
6I CCE I8I2.

62 Cf. CCE I803-I8II.

63 Cf. CCE I8I2.

64 Cf. I Co I3, I3.

65 CCE I8I5.

66 Cf. I Tes 5, 8.
} 
fe y caridad. En el imaginario religioso da la impresión que el ser cristiano es solo creer y amar, pero en el contexto actual parece ser que esperar es mucho más difícil, porque implica anclar la vida misma en el Dios de Jesucristo que es esperanza y que nos pide con "la alegría de la esperanza estar constantes en la tribulación" ${ }^{67}$, "esperar contra toda esperanza" ${ }^{68}$.

La existencia cristiana es entonces, y lo reafirmamos, una existencia en la fe, la esperanza y la caridad. En la esperanza está implícitamente presente la fe como confianza, como apoyarse en Dios. No son tres virtudes diferentes y separadas, sino tres aspectos de una única actitud cristiana, por lo tanto, es el don del Espíritu Santo ofrecido a toda persona que en la fe se abre a Cristo ${ }^{69}$.

Teniendo clara la entraña de la esperanza inseparable de la fe y la caridad, nos disponemos a presentar las consecuencias que esto tiene al considerar a la familia como una comunidad no sólo de vida y amor, sino también de fe y esperanza para sí misma, para la Iglesia y la humanidad, teniendo en cuenta que ella, como primer lugar de socialización humana, puede convertirse en maestra de esperanza.

\section{La familia cristiana, signo y esperanza para el mundo}

El título de este apartado nos invita a profundizar en las consecuencias fundamentales para la familia cristiana de ser signo y a la vez peregrina en la esperanza cristiana. Ella es signo del Dios trinitario cuando es prueba en el mundo de que es posible vivir desde Cristo, desde el amor con el que ama Cristo y desde la fe y esperanza que sostiene su peregrinar por el mundo.

Si hay pocas familias cristianas en la Iglesia y en la sociedad, flaquea la esperanza, porque quiere decir que hay pocos lugares para la transparencia de Cristo, lugares en que la vivencia del amor trinitario que inspira Dios entre los hombres se haga visible. Lugares en que a través del amor solidario y compasivo inviten a confiar en Dios y esperar en Él.

\footnotetext{
67 Cf. Rom I2, 12.
}

68 I Pe 3, I5.

69 Cf. CCE I83o. 
Conformar una familia cristiana en el contexto actual es signo ya de esperanza, porque exige del cristiano afrontar la crisis en la que se halla la familia actual con juicio, purificación y decisión, tomando conciencia de que en la aridez en la que nos encontramos se acrisolan la fe, la esperanza y el amor. La familia tiene a su favor que, aún con la crisis matrimonial existente, el proyecto vital de los jóvenes sigue siendo el de conformar un matrimonio y dar inicio a una familia, el de encontrar una pareja armónica y lograda, en medio de las inseguridades y cambios de la vida moderna. En medio de la crisis de soledad y egoísmo, la familia se percibe como el lugar en el cual encontrar aceptación incondicional, compartir fraterno, seguridad y experiencia del amor humano y divino ${ }^{70}$.

Al menos a nivel pastoral, existe una mayor toma de conciencia del significado sacramental del vínculo matrimonial por el cual la familia cristiana está invitada a ser en el mundo signo del plus que la hace distinta a la familia natural. Mediante el sacramento que la funda, la familia cristiana se convierte en sacramento de Dios en el mundo, en signo de la proximidad de Dios, de manera que "los cónyuges entran en contacto especial con Dios y con su amor, de modo que el amor de Dios refuerce, acompañe y lleve a plenitud su propio amor. Por ello su amor es expresión específica del amor de Dios, porque el amor conyugal 'ha nacido de la fuente divina de la caridad y está formado a semejanza de la unión de Cristo con la Iglesia' (GS 48,2)"7I.

De esta sacramentalidad, de este "ser signo" de la cercanía de Dios al mundo, de ser el lugar de la acogida de Dios al ser humano y de gustación de su amor, la familia cristiana encuentra la fuente de su espiritualidad matrimonial. Se trata de tomar en serio el matrimonio como lugar concreto del seguimiento de Jesús, y de fomentar una confianza sin límites en la voluntad y capacidad salvífica de Dios, que Jesús proclamó y en la que él mismo vivió. Cuando los matrimonios viven en este espíritu, pueden convertirse en un lugar y en camino de salvación.

Esta espiritualidad familiar se alimenta de la verdad de la familia como comunidad de esperanza y se ejercita en la oración. No sin

70 Michael Knapp, "El matrimonio como forma de vida cristiana", Selecciones de Teología I98 (201I) I47-I54, p. I47. 7I Ibíd., I49. 
razón el número 6oa de la FC llama a los padres cristianos "maestros de oración" cuyo deber específico es el educar a sus hijos en la plegaria, de introducirlos progresivamente en el misterio de Dios y en el coloquio personal con él.

Ante las dificultades que se ciernen sobre la familia cristiana, ella está llamada a ser signo de esperanza en el Dios de la esperanza. La Iglesia invita recurrentemente a las familias cristianas a apoyarse en la fe y la esperanza, animándolas a invocar con oración perseverante la ayuda divina, acudiendo sobre todo a la fuente de gracia y de caridad que es la Eucaristía, a no desanimarse frente al pecado, sino que ante éste hay que recurrir con humilde perseverancia a la misericordia de Dios, que se concede en el sacramento de la penitencia y a confiar en la realización de la plenitud de la vida conyugal, descrita por el Apóstol: "Maridos, amad a vuestras mujeres como Cristo amó a su Iglesia [...]"72.

En definitiva, la familia es signo de esperanza para el mundo si toma conciencia de su iconalidad trinitaria. Ella es en el mundo testimonio del amor misericordioso y compasivo de Dios, si deja traslucir un amor esperanzado y si su caridad habla de su fe y de su esperanza. A la luz de la fe y en virtud de la esperanza, nos dice la FC 65b, la familia cristiana participa, en comunión con la Iglesia, en la experiencia de la peregrinación terrena hacia la plena realización del Reino de Dios.

La Iglesia tiene claro que esta propuesta esperanzadora no se limita solamente a las familias cristianas, sino hacia el conjunto de familias en general, y en particular aquellas que, aun siendo de fundación matrimonial, están alejadas o se hallan en situaciones difíciles e irregulares. Para todas ellas la Iglesia tendrá palabras de verdad, de bondad, de comprensión, de esperanza, de viva participación en sus dificultades a veces dramáticas; ofrecerá a todos su ayuda desinteresada, a fin de que puedan acercarse al modelo de familia que ha querido el Creador "desde el principio" y que Cristo ha renovado con su gracia redentora ${ }^{73}$.

Así mismo, la familia cristiana es signo de esperanza para el mundo porque ella misma peregrina en la esperanza cristiana. La fe que 
nace de la esperanza le permite aprender a esperar en el Dios de la esperanza y la misericordia con unas características concretas que le dan rostro en el mundo como una comunidad eminentemente escatológica. Nos inspiramos en el pensamiento de Moltmann, que describe cuáles deberían ser las características de la comunidad cristiana desde la escatología y las aplicamos a la familia.

a. La familia es una comunidad que tiene una misión que da identidad a los miembros de la familia como creyentes y "esperantes". Tal misión es propiamente el anuncio, la predicación del Evangelio, que no es transmisión de sabiduría y doctrinas, tampoco es tradición de caminos y cambios de vida según la ley, sino es anuncio, revelación y proclamación de una acontecimiento escatológico, la revelación del dominio del resucitado sobre el mundo que libera al hombre, en la fe y la esperanza, para la salvación venidera $^{74}$. El padre Gustavo Baena lo expresa así:

La esperanza cristiana como componente esencial de ese todo que se llama el Evangelio, cuya realidad histórica es la existencia cristiana es la comunidad, es un don que consiste en el Resucitado mismo dándosenos por su Espíritu y que nos hace capaces de superar con paciencia toda resistencia que se oponga a nuestra autotrascendencia o al amor incondicional al "otro"75.

b. La segunda característica es que se trata de una familia-comunidad en éxodo, es decir, un grupo incapaz de acomodarse del todo. Su esperanza le hace oponerse a los valores sociales contrarios a la vida, al amor y a la propia esperanza cuando se mezcla con ideologías. La moderna integración de todos con todos no cuaja en ella. Se inicia, por lo tanto con la sociedad un diálogo lleno de conflictos, pero fecundo, ya que solo allí donde su resistencia la muestra como un grupo no conquistable, pueden los cristianos comunicar a esta sociedad su propia esperanza ${ }^{76}$.

74 Gal I:2 ss; I Cor 9:I; I Cor 15:8. Cf. Moltmann, Teología de la Esperanza..., 353-392.

75 Gustavo Baena, "La esperanza en la vida cristiana. Dimensión bíblica”, Theologica Xaveriana I54 (Bogotá, 2005$), 222$.

76 Cf. Jürgen Moltmann, Teología de la Esperanza..., 436. 
La familia cristiana como la primera comunidad eclesial y social está llamada a ofrecer calor y cercanía humanos, vecindad y hogar, comunidad libre de fines y llena de sentido, "auténtica" de relaciones interpersonales cargadas de espontaneidad y de apertura total a la multiplicidad de soluciones y situaciones siempre nuevas ${ }^{77}$. Solo así puede brillar la verdad de ser un lugar de esperanza y sentido humano.

c. La familia-comunidad está llamada a ser cuerpo del Cristo crucificado y resucitado. Está llamada a ser y comprenderse como comunidad de aquellos que, en virtud de la resurrección de Cristo, aguardan el Reino de Dios y se hallan definidos en su vida por esta espera. En este punto es importante citar los aportes de Scannone y de Sánchez que, junto con Moltmann, presentan una cristología desde el sufrimiento, desde una teología de la cruz, que reflexiona la acción de Dios en la historia desde las víctimas, desde su sufrimiento:

Según el Nuevo Testamento la citada oración y queja de Jesús: "Dios mío, Dios mío, ¿Por qué me has abandonado?" (Mt 27:46; Mc 15:34), que simboliza, condensa y excede infinitamente las justas quejas de las víctimas, no acaba allí, sino que se abre a la "esperanza contra toda esperanza", expresada en el "Padre, en tus manos encomiendo mi espíritu” (Lc 23:46). Así se describe la actitud de fe, confianza y amorosa entrega de Jesús, que muestra, no demuestra, la respuesta práctica, no teórica, a la "tragedia” (¡no en sentido griego!) del "justo sufriente" 78 .

d. Por último es una familia-comunidad que no se identifica con los milenarismos secularizados, ni con los mesianismos políticos que pretenden en el presente realizar las esperanzas de la sociedad y ocupar el trono de Dios. La verdadera esperanza familiar está a la expectación del futuro en el contexto escatológico del final de la nueva creación del mundo. Es una imagen de esperanza en 
la resistencia y el sufrimiento, fundamentada en la entrega a la muerte en la cruz y en la resurrección de Cristo de entre los muertos que es la manifestación del nuevo y eterno eón ${ }^{79}$.

\section{Portadora de sentido de vida}

Desde lo anterior queda claro que si la familia recobra su ser y talante esperanzador, puede contribuir concretamente a ser portadora y educadora en el sentido de la vida. En la confianza de que el mundo tiene un futuro en Dios, porque Dios está en él y más bellamente aún, como dice Josep Vives:

[Este mundo tiene sentido] porque Dios es el fundamento último de la esperanza cristiana. Dios tiene esperanza en nosotros. Me atrevería a decir que, en un cierto sentido, Dios practica con el mundo las tres virtudes que nosotros hemos de practicar con él: Dios tiene fe en el mundo, porque es obra suya; Dios espera en el mundo, porque espera que su gracia triunfará finalmente sobre la irresponsabilidad humana. Y todo ello porque Dios ama al mundo, porque es fruto de su amor. Más todavía. Dios ama gratuitamente, porque sí, porque es bueno, no porque nosotros hayamos merecido su amor, ni sólo en la medida en que lo hayamos merecido ${ }^{80}$.

La anterior visión nos parece que es el fundamento último de la esperanza en la que la familia se sostiene. No es que la familia crea, espere y ame a Dios, es que Dios (desde el acontecimiento de Cristo, muerto y resucitado) por toda la eternidad ha creído, esperado y amado al ser humano. Dios se convierte entonces en el centro de la esperanza familiar.

Esperanza y sentido de la vida van unidos. De tal manera que la pregunta por el sentido de la vida en el cristiano es la pregunta sobre su Esperanza. Esta relación la presenta de modo particular Ruiz de la Peña, para quien la pregunta por el sentido coincide con la escatología (y como vimos, la escatología es esperanza en su significado más puro), ya que ésta versa sobre los contenidos definitivos del

79 Jürgen Moltmann, La venida de Dios: escatología cristiana, (Salamanca: Ediciones Sígueme, 2004), 216.

80 Josep Vives, "Esperanza cristiana y compromiso liberador...", 465. 
cumplimiento de la Palabra; tanto la pregunta por el sentido como la escatología remiten a un objetivo común: "el último sentido"\$1.

Para un cristiano, explica Ruiz de la Peña, la pregunta por el sentido es, entonces, la pregunta sobre la razón de su fe, sobre su esperanza que no se define por una idea, o en conseguir determinadas cosas, sino que su esperanza es una persona: Cristo Jesús que lo fortalece y lo acompaña en su vida, y esta fe le permite observar la realidad de manera distinta. Por esto, cuando nos referimos al sentido de vida desde el cristianismo, lo hacemos desde el anuncio escatológico, es decir, de la esperanza en Jesús, el Cristo, para los que creen y se sostienen en él ${ }^{82}$.

Este permanecer sostenidos en el amor de Dios y la verdad de Cristo es la raíz de la esperanza familiar. Aunque la sociedad ofrezca propuestas y perspectivas seductoras de sentido, de vivencia de un amor libre y sin responsabilidad hacia el otro, la familia desde su discernimiento ético en Cristo, desde la Verdad de Cristo, proclama la dignidad de la persona humana, desde su "magisterio familiar", inspirado en el proyecto familiar como designio de Dios. "Volver a comprender el sentido último de la vida y de sus valores fundamentales es el gran e importante cometido que se impone hoy día para la renovación de la sociedad"83.

Ante el mundo que necesita una palabra de esperanza y de luz, y ante su aparente sinsentido, la familia cristiana se presenta con gran riqueza. Ella es sostenida por el amor trinitario de Dios que es la raíz de su esperanza, con la confianza de este peregrinar por el mundo, por sus realidades, "sólo es posible si se cree y espera que el todo de lo que es, el todo de nuestra vida experimentable, está abarcado por el misterio sagrado del amor eterno" ${ }^{4}$.

Misterio sagrado del amor eterno que llama a la familia cristiana a configurarse desde el amor divino. La misma vida de la familia asumiendo lo que conlleva la existencia: alegrías y dolores, esperanzas y

\footnotetext{
8I Cf. Juan Luis Ruiz de la Peña, El último sentido, (Madrid: Marova, 1979), 29-30.

82 Cf. Ibíd., 55-6I.

83 (cf. FC 8)

84 Karl Rahner, Curso fundamental sobre la fe: Introducción al concepto de cristianismo, (Barcelona: Herder, 2003, 6 ed.), 467.
} 
tristezas, nacimientos y cumpleaños, aniversarios de la boda de los padres, partidas, alejamientos y regresos, elecciones importantes y decisivas, muerte de personas queridas, entre otros, son momentos propicios para captar la intervención del amor de Dios en la historia de la familia. Momentos en que la práctica del amor esperanzado se hace visible en el seno familiar y en el que la oración familiar debe señalar desde la acción de gracias, la imploración, de abandono confiado de la familia al Padre común que está en los cielos. Además, la dignidad y responsabilidades de la familia cristiana en cuanto Iglesia doméstica solamente pueden ser vividas con la ayuda incesante de Dios, que será concedida sin falta a cuantos la pidan con humildad y confianza en la oración ${ }^{85}$.

Desde esta perspectiva la familia cristiana como comunidad de fe y esperanza está llamada a vivir según la denominación precisa del amor que es la paciencia que todo lo espera y todo lo soporta ${ }^{86}$. Gustavo Baena define esta paciencia de la esperanza como el amor mismo o la autotrascendencia en función del otro por encima de todas las adversidades que nos vienen y por encima de nuestras tendencias egoístas que nos impulsan a encerrarnos dentro de los límites de nuestra propia finitud. Amar es esperanza, es no cansarnos de amar, y para ello nos apoyamos en el poder gratuito del Espíritu del Resucitado que subsiste en nosotros mismos y nos hace capaces de la paciencia de la esperanza ${ }^{87}$.

Es decir, vivir con sentido de la vida en un contexto de auténtica vida familiar y educar en ese sentido es la misión de la familia como comunidad de fe y esperanza. Esto significa, concretamente, fundar la vida, el amor, la fe, la esperanza en Cristo, ya que como observamos anteriormente, el sentido de la vida para el cristiano está en Cristo. No en un sentido abstracto, sino en un estilo de vida que expresa que la existencia está siendo sostenida por Aquél en quien se ha puesto la vida y la esperanza.

Se necesitan familias cristianas que diariamente expresen este sentido último, la razón de seguir en el mar de inseguridades que nos

\footnotetext{
85 Cf. FC 59c.

86 Cf.I Co 13,7 .

87 Cf. Baena, "La esperanza en la vida cristiana. Dimensión bíblica...”, 220-22I.
} 
presenta la sociedad actual. Familias enamoradas de Cristo que vivan ese amor entre los miembros de la familia y que lo proyecten hacia las demás familias, hacia la Iglesia y la sociedad. Familias que parafraseando a Horacio, "aunque el cielo se derrumbe las ruinas las encontraran en pie”, sostenidas por su fe y esperanza.

\section{El retorno a la verdadera esperanza, una lectura de Spe salvi}

Lo dicho hasta ahora sobre la familia entendida como comunidad de fe y esperanza nos ha supuesto un camino de análisis de la cultura actual ensombrecida por la desesperanza y la frustración de sus proyectos políticos e ideológicos, causando un sinsabor antropológico de soledad y egoísmo que ha ocultado el verdadero rostro de la esperanza cristiana.

También tratamos de entrar, desde la teología y el magisterio, en lo profundo de la esperanza cristiana, en su corazón, para que brille también la misión de la familia de vivir bajo el signo y el peregrinaje de la esperanza cristiana y así hacer creíble el anuncio gozoso y radiante de un horizonte de esperanza que dé motivos ante la fatiga de vivir.

La primera encíclica de Benedicto XVI, Deus caritas est nos ayudó a profundizar en el significado del amor y de las consecuencias en el seno de la familia que se comprende desde este amor, la segunda encíclica Spe salvi, publicada el día 30 de noviembre de 2007, nos ayudará, desde la perspectiva del diálogo con la cultura actual, a fijar el horizonte desde el cual la familia cristiana se puede comprender también como una familia llamada a ser una comunidad de fe y esperanza. Aunque Spe salvi no se refiere directamente a la familia, su contenido sobre la esperanza cristiana nos permitirá ver claramente en qué consiste esta virtud teologal y allanará el camino para hacer de esta virtud el sello de identidad de las familias cristianas llamadas a ser comunidades de esperanza.

Hay cuatro grandes temas en la encíclica que de alguna manera hemos tratado en este capítulo y que el papa presenta con gran interés, por lo que nos serán motivo de detenimiento: el primero se refiere al eclipse de la esperanza cristiana en la cultura actual y a la crítica moderna de la misma; el segundo y más importante, tiene que ver con la relación intrínseca entre la fe y la esperanza; el tercer tema, si 
lo podemos llamar así, son los testigos de la esperanza cristiana; y el cuarto es la presentación de los "lugares" de aprendizaje y del ejercicio de la esperanza.

Sin pretensión de estudiarlos a fondo, presentaremos los contenidos más importantes de estos cuatro temas que conectan con lo que hemos dicho anteriormente sobre la familia como comunidad de esperanza.

El primer tema lo desarrolla el papa en los números I6 al 23 en los que señala la transformación de la fe-esperanza cristiana en el tiempo moderno. El papa se pregunta cómo se ha desarrollado la idea de que el mensaje de Jesús es estrictamente individualista y dirigido solo al individuo y cómo se ha llegado a interpretar la "salvación del alma" como huida de la responsabilidad respecto a las cosas en su conjunto y, por consiguiente, a considerar el programa del cristianismo como búsqueda egoísta de la salvación que se niega a servir a los demás ${ }^{88}$.

La anterior pregunta le sirve al papa para analizar los cambios fundamentales de la época moderna a través del pensamiento de Bacon como principal exponente ${ }^{89}$. Explica el hecho de que en la época moderna la esperanza cristiana se ha visto en gran medida eclipsada o reemplazada en la conciencia de muchos hombres por las ideologías modernas del progreso, "ahora la esperanza se llama fe en el progreso"90. La aparente pujanza histórica de estas ideologías, y la modelación de la mentalidad colectiva, explica que incluso en los casos en los que la fe cristiana ha seguido siendo fuente de esperanza, ésta se haya retraído a la esfera privada e individual.

Entendida la esperanza como fe en el progreso, la razón y la libertad jugarán un papel importante en la secularización de la esperanza cristiana:

Al mismo tiempo, hay dos categorías que ocupan cada vez más el centro de la idea de progreso: razón y libertad. El progreso es sobre todo un progreso del dominio creciente de la razón, y esta razón es considerada obviamente poder del bien y para el bien. El

88 Cf. SS I6.

89 Cf. SS 17.

$90 \mathrm{SS}$ I7. 
progreso es la superación de todas las dependencias, es progreso hacia la libertad perfecta. También la libertad es considerada sólo como promesa, en la cual el hombre llega a su plenitud ${ }^{91}$.

La historia ha asistido principalmente, en sentido socio-político, a dos concreciones de esta fe en el progreso: la Revolución francesa como intento de restaurar el dominio de la razón y la libertad ${ }^{92}$ y la revolución proletaria que da el salto revolucionario hacia las mejoras de las condiciones precarias de los trabajadores instadas por el avance cada vez más rápido del desarrollo técnico y de la industrialización.

Al haber desaparecido la verdad del más allá, se trataría ahora de establecer la verdad del más acá. La crítica del cielo se transforma en la crítica de la tierra, la crítica de la teología en la crítica de la política. El progreso hacia lo mejor, hacia el mundo definitivamente nuevo, ya no viene simplemente de la ciencia, sino de la política; de una política pensada científicamente, que sabe reconocer la estructura de la historia y de la sociedad, y así indica el camino hacia la revolución, hacia el cambio de todas las cosas $[\ldots]^{93}$.

El papa enfatiza que el error de Marx no consistió solo en no haber ideado los ordenamientos necesarios para el nuevo mundo, su error es de fondo pues ha olvidado que el hombre es siempre hombre. Ha olvidado al hombre y ha olvidado su libertad. Ha olvidado que la libertad es siempre libertad, incluso para el mal. Creyó que, una vez solucionada la economía, todo quedaría solucionado. Concluye magistralmente el papa, su verdadero error es el materialismo. En efecto, el hombre no solo es el producto de condiciones económicas y no es posible curarlo solo desde fuera creando condiciones económicas favorables ${ }^{94}$.

Se hace necesario una necesaria autocrítica de la edad moderna en diálogo con el cristianismo y con su concepción de la esperanza. Ante todo hay que preguntarse: ¿qué significa realmente "progreso"?; ¿qué es lo que promete y qué es lo que no promete? El papa remite al

9I SS I8.

92 Cf. SS i9.

$93 \mathrm{SS} 2 \mathrm{O}$.

94 SS 2 I. 
pensamiento de Adorno, quien expresó de manera drástica la incertidumbre de la fe en el progreso, su ambigüedad, sus posibilidades para el bien y sus posibilidades abismales para el mal. El Pontífice clama por un progreso técnico que corresponda con un progreso en la formación ética del hombre, con el crecimiento del hombre interior y no con un progreso que sin ética es una amenaza para el hombre y para el mundo ${ }^{95}$.

También urge una recta comprensión de la razón y la libertad. La razón del poder y del hacer para que impulse el progreso, necesita el crecimiento moral de la humanidad y su integración mediante la apertura de la razón a las fuerzas salvadoras de la fe y al discernimiento entre el bien y el mal. Sólo de este modo se convierte en una razón realmente humana, sólo se vuelve humana si es capaz de indicar el camino a la voluntad, y esto sólo lo puede hacer si mira más allá de sí misma ${ }^{96}$.

Para que la libertad adquiera su esplendor debe estar determinada por un común e intrínseco criterio de medida, que es fundamento y meta de nuestra libertad: Dios. Por eso el "hombre necesita a Dios, de lo contrario queda sin esperanza" ${ }^{97}$. La historia ha demostrado que un "reino de Dios" instaurado sin Dios por el hombre desemboca inevitablemente en "el final perverso". De allí que Dios mismo entra realmente en las cosas humanas, Él toma la iniciativa. Por eso la razón necesita de la fe para llegar a ser ella misma: razón y fe se necesitan mutuamente para realizar su verdadera naturaleza y misión ${ }^{98}$.

El segundo tema importante para nuestro estudio es el de la relación intrínseca entre la fe y la esperanza ${ }^{99}$. En el número 2 de la encíclica, el papa hace notar esa relación al afirmar que "esperanza" es una palabra central de la fe bíblica, hasta el punto de que en muchos pasajes las palabras "fe" y "esperanza" parecen intercambiables y para esto se remite a las citas de Hebreos I0:22-23 y i Pedro 3:I5 las cuales presentan de manera concisa tal relación. Ya el papa en su primera

\footnotetext{
95 Cf. SS 22.

96 Cf. SS 23.

97 Ef. 2,I2.

98 Cf. SS 23.

99 NN. 2-9.
} 
encíclica había interrelacionado las tres virtudes para hablar de la opción por la justicia y la caridad, aquí las interrelaciona a partir de otro matiz que observaremos a continuación ${ }^{100}$.

Jacinto Núñez, en su análisis sobre el fundamento bíblico de la Spe Salvi, hace notar que en los textos anteriores, la "confusión" de fe y esperanza es una señal clara de que la experiencia creyente, que resumimos con la palabra "fe", tiene un componente esencial de esperanza. De allí que el papa se refiera a que el haber recibido como don una esperanza fiable fue determinante para la conciencia de los primeros cristianos ${ }^{\mathrm{IOI}}$.

La esperanza de la fe es la novedad que trae Cristo. A la vida anterior en la que se vivía se puede decir que le faltaba la esperanza y, por lo tanto, a Dios como fuente de la esperanza. Esto es lo que Pablo les recuerda a los cristianos de Éfeso cuando afirma que "antes del encuentro con Cristo no tenían en el mundo ni esperanza ni Dios" ${ }^{\text {"or }}$. En el mismo sentido se dirige a los Tesalonicenses con estas palabras: "No os aflijáis como los hombres sin esperanza"

La esperanza de la fe es un elemento distintivo de los cristianos. Ellos tienen un futuro: no es que conozcan los pormenores de lo que les espera, pero saben que su vida, en su conjunto, no acaba en el vacío. Sólo cuando el futuro es cierto como realidad positiva, se hace llevadero también el presente. El cristianismo conlleva más que una "buena noticia", una comunicación que comporta hechos y cambia la vida, ya que quien tiene esperanza vive de otra manera, pues se le ha dado una vida nueva ${ }^{104}$.

La esperanza que propone el papa es aquella que redime, que da la vida nueva, que surge del conocimiento de Dios, del encuentro real con él. Una esperanza que cuando se experimenta hace renacer al ser humano, lo redime y lo hace anunciarla a otros para que también la

\footnotetext{
IOo Cf. DCE 39

IOI (SS 2)Cf. Jacinto Núñez, "El fundamento bíblico de Spe salvi”, en: Jesús García, José-Román Flecha (coords.), Salvados en esperanza. Comentarios a la encíclica de Benedicto XVI Spe salvi, (Salamanca: Publicaciones Universidad Pontificia de Salamanca, 2008), 80.

IO2 (Ef 2,I2)

IO3 (I Ts 4,I3) (cf. SS 2 y 5)

IO4 (Cf. SS 2).
} 
experimenten y transforme sus vidas y, con ella, a la sociedad misma, pero desde dentro ${ }^{\mathrm{IO}}$, conscientes de que la sociedad actual no es su ideal sino que se pertenece a una sociedad nueva hacia la cual se está en camino y que es anticipada en su peregrinación ${ }^{106}$.

Cristo es entonces nuestra esperanza, nos dice quién es en realidad el hombre y qué debe hacer para ser verdaderamente hombre. Él nos indica el camino y este camino es la verdad. Él mismo es ambas cosas, y por eso es también la vida que todos anhelamos. Él indica más allá de la muerte y por eso es el verdadero maestro de vida. Él mismo ha recorrido el camino de la muerte, ha bajado al reino de la muerte, la ha vencido y ha vuelto para acompañarnos ahora y darnos la certeza de que, con Él, se encuentra siempre un paso abierto. Saber que existe Aquél que me acompaña, incluso en la muerte, y que con

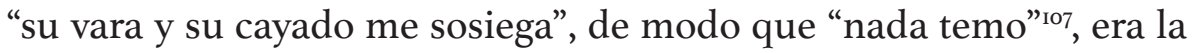
nueva "esperanza" que brotaba en la vida de los creyentes ${ }^{108}$.

Sobre la definición clásica de fe sacada de Heb II,II, en el ámbito protestante y católico que la define como el "estar firmes en lo que se espera, estar convencidos de lo que no se ve”, el papa explicará que aunque no es erróneo, sobre esta definición sí hay que hacer precisiones, pues el término griego usado (elenchos) no tiene el valor subjetivo de "convicción", sino el significado objetivo de "prueba", es decir, la fe no es solamente un tender de la persona hacia lo que ha de venir, y que está todavía totalmente ausente; la fe nos da algo. Nos da ya ahora algo de la realidad esperada, y esta realidad presente constituye para nosotros una "prueba" de lo que aún no se ve.

Ésta atrae al futuro dentro del presente, de modo que el futuro ya no es el puro "todavía no". El hecho de que este futuro exista, cambia el presente; el presente está marcado por la realidad futura, y así las realidades futuras repercuten en las presentes y las presentes en las futuras ${ }^{109}$.

I05 (cf. SS 3 )

I06 Cf. SS 4 .

I07 Cf. Sal 23, 4 .

Io8 Cf. SS 6.

IO9 Cf. SS 7 . 
Heb Io:34, nos presenta lo anterior de manera radical en la vida de los cristianos cuya fe impregnada de esperanza les permite afrontar la persecución, el sufrimiento con alegría, sabiendo que tenían bienes mejores y permanentes que nadie les podía arrebatar. Esa riqueza es la riqueza de la fe que otorga en la vida una base nueva, un nuevo fundamento sobre el que apoyarse, de tal manera que lo demás queda relativizado ${ }^{\text {IIO }}$.

Otro texto de Heb I0:36-39 agrega además el ingrediente de la Hypomoné, que se traduce normalmente por "paciencia", perseverancia, constancia. Es decir, el creyente necesita saber esperar soportando pacientemente las pruebas para poder "alcanzar la promesa" Hypomoné indica también una esperanza vivida, una existencia basada en la certeza de la esperanza. En Cristo, la espera en Dios adquiere una nueva certeza, ya que Dios se ha manifestado en Él. Se esperan las realidades futuras a partir de un presente ya entregado. Es la espera, ante la presencia de Cristo, con Cristo presente, de que su Cuerpo se complete, con vistas a su llegada definitiva. Distinto a la expresión hypostolé, que expresa el retraerse de quien no se arriesga a decir abiertamente y con franqueza la verdad quizás peligrosa. Este esconderse ante los hombres por el espíritu de temor, lleva a la "perdición" "I2.

El tercer tema es el de los testigos de la esperanza cristiana, aquellos cuya esperanza, al ser tocada por Cristo, ha brotado esperanza para otros que vivían en la oscuridad y en la desesperanza. Testigos que han demostrado que la nueva vida en Cristo posee realmente "sustancia" que suscita vida para los demás, su vida y su comportamiento son de hecho una "prueba" de que las realidades futuras, la promesa de Cristo, no es solamente una realidad esperada, sino una verdadera presencia ${ }^{\mathrm{II}}$.

El papa, a lo largo de la encíclica, nos presenta el ejemplo de estos testigos en los que aparecen diferentes perspectivas de la esperanza cristiana. En el número 3 narra la historia de vida de Josephine Bakhita quien fue vendida, esclava y maltratada pero al conocer que

\footnotetext{
IIO Cf. SS 8.

III Heb Io, 36 .

II2 Heb Io, 39, cf. SS 9.

II3 Cf. SS 8.
} 
Dios la amaba, se sintió feliz y llena de esperanza porque era hija de Dios. También nos presenta el ejemplo de San Agustín (29) quien fue adalid de la esperanza cristiana en el contexto de conmoción del final del Imperio romano, sirviendo como obispo a la gente sencilla. Por su parte la vida del cardenal Nguyen Van Thuan (32) está impregnada del esperar en Dios, ya que durante sus trece años de cautiverio, la oración, la escucha de Dios y el diálogo con Él lo sostuvieron en medio de esa cruel realidad del encierro. Por último recoge el testimonio del mártir vietnamita Le-Bao-Thin (37) quien en una carta cita frases de una profunda esperanza: "No estoy solo, sino que Cristo está conmigo", "en medio de esta tempestad echo el ancla hasta el trono de Dios, esperanza viva de mi corazón".

El cuarto tema importante de la encíclica tiene que ver la presentación de los "lugares" de aprendizaje y del ejercicio de la esperanza. El primero de ellos es la oración como escuela de la esperanza (32-34): quien reza hace un profundo acto de fe y confianza, ya que "si me veo relegado a la extrema soledad... (Dios me acompaña); el que reza nunca está totalmente solo". La oración mantiene la esperanza, "esa gran esperanza que no se apaga ni siquiera en las noches de la soledad" "I4.

El número 33 nos presenta en siete puntos toda una pedagogía de la oración cristiana. La oración nos hace conscientes de nuestra realidad de hijos que se dirigen a un Padre común, nos compromete con la historia; nos inspira lo que debemos pedir; en ella están presentes los demás y su bien; nos impulsa a pedir grandes cosas; nos purifica de nuestros deseos y esperanzas y nos puede liberar de las mentiras ocultas con las que nos engañamos a nosotros mismos ${ }^{\mathrm{II}}$.

Debe ser una oración, además de personal, ayudada por la rica tradición de oración de la Iglesia, de los santos y la oración litúrgica, en una interacción entre oración pública y oración personal. Así podemos hablar a Dios, y así Dios nos habla a nosotros. Esta oración

\footnotetext{
II4 SS 32.

II5 Cf. Flecha, "Esperanza y tarea moral", en: García Rojo y Flecha (coords.), Salvados en esperanza. Comentarios a la encíclica..., $\mathrm{I70}$.
} 
nos purifica, nos hace capaces de la gran esperanza y nos convierte en ministros de la esperanza para los demás ${ }^{\mathrm{II}}$.

El segundo lugar de aprendizaje de la esperanza es actuar y sufrir (35-40). El papa comienza con una afirmación importante y es que toda actuación seria y recta del hombre es esperanza en acto. Esta actuación debe estar iluminada por la luz de aquella esperanza más grande que no puede ser destruida ni siquiera por frustraciones en lo pequeño, ni por fracaso en los acontecimientos de importancia histórica. Mi vida personal y la historia en su conjunto están custodiadas por el poder indestructible del amor, gracias al cual todo tiene sentido e importancia, sólo una esperanza así puede dar ánimo para actuar y continuar. ${ }^{\text {II7 }}$

Al igual que el obrar, también el sufrimiento forma parte de la existencia humana, debemos hacer todo lo posible para superar el sufrimiento, pero extirparlo del mundo por completo no está en nuestras manos, esto sólo podría hacerlo Dios. Con la fe en la existencia de este poder, ha surgido en la historia la esperanza de la salvación del mundo, esperanza que nos da el valor para ponernos de parte del bien, aun cuando parece que ya no hay esperanza ${ }^{\text {II8 }}$.

Lo que cura al hombre no es esquivar el sufrimiento y huir ante el dolor, sino la capacidad de aceptar la tribulación, madurar en ella y encontrarle un sentido mediante la unión con Cristo ${ }^{119}$. La sociedad está llamada a aceptar a los que sufren y contribuir a que el sufrimiento sea compartido y sobrellevado también interiormente, si no es así, es una sociedad cruel e inhumana. Así mismo, la persona debe asumir el sufrimiento con sentido, descubriendo en él un camino de purificación y maduración, un camino de esperanza ${ }^{120}$.

Sufrir con el otro, por los otros; sufrir por amor de la verdad y de la justicia; sufrir a causa del amor y con el fin de convertirse en una persona que ama realmente, son elementos fundamentales de humanidad, cuya pérdida destruiría al hombre. Esto es posible si estamos

\footnotetext{
II6 Cf. SS 34 .

II7 Cf. SS 35.

II8 Cf. SS 36.

II9 SS 37 .

I2O SS 38
} 
aferrados a la gran esperanza ${ }^{\mathrm{I2I}}$ y si en el día a día ofrecemos las pequeñas dificultades, dándoles así un sentido salvífico ${ }^{122}$.

Por último, los números 4I-48 nos presentan el Juicio como el último lugar de aprendizaje de la esperanza. Esta imagen del Juicio, ya desde los primeros tiempos, era una llamada a la conciencia de los cristianos, que estimulaba su responsabilidad y orientaba su esperanza en la justicia de $\operatorname{Dios}^{123}$. Ante las desviaciones de la idea sobre el Juicio en la época moderna ${ }^{124}$ se hace necesaria la vuelta a la fe en la justicia final del inocente, a la "revocación" del sufrimiento pasado y a la reparación que restablece el derecho ${ }^{125}$. Solo Dios puede crear justicia. Y la fe nos da esa certeza: Él lo hace ${ }^{\mathrm{I} 26}$.

Los últimos cuatro números se refieren a la fe cristiana en el más allá, al infierno como la persistencia definitiva en la mentira por parte de personas que han vivido para el odio ${ }^{\mathrm{I27}}$, al purgatorio ${ }^{\mathrm{I2} 8}$, a la justicia de Dios que es esperanza tanto porque es justicia, como porque es gracia $^{129}$, y al alcance misterioso de nuestra oración por los difuntos, a nuestra intercesión que les acompaña, siendo verdadero entonces que nuestra esperanza es siempre y esencialmente también esperanza para los otros ${ }^{130}$.

\section{La familia: escuela de amantes, "esperantes" y creyentes}

Dado lo anterior, podemos afirmar que es posible que la familia se constituya en el lugar privilegiado de la vivencia y educación en la fe y la esperanza cristiana. El verdadero rostro de la familia es ser un espacio en el cual se vive y se educa en ser hombres y mujeres amantes, “esperantes" y creyentes en el Dios vivo y verdadero. Aunque estas palabras no sean frecuentemente utilizadas, habría que volver a ellas

\footnotetext{
I2I SS 39.

122 Cf. SS 40.

I23 SS 4 I.

124 Cf. SS 42.

I25 Cf. SS 43 .

I26 SS 44 .

${ }_{127}$ Cf. SS 45.

I28 Cf. SS 46.

I29 Cf. SS 47 .

I30 Cf. SS 48 .
} 
para descubrir la riqueza humana y trascendental de la familia para la Iglesia y la sociedad.

La anterior comprensión se encuentra presente en los textos teológicos y magisteriales, pero hay que insistir en esta dimensión teológica de la familia. La verdadera teología de la familia es aquella que comprende a la familia como el lugar querido por Dios para vivir en el amor, la esperanza y la fe.

Pablo VI lo había afirmado implícitamente al comentar que el anuncio del Evangelio es el servicio que la Iglesia presta a la comunidad cristiana e incluso a la humanidad. Anuncio que se realiza "exaltados por la esperanza, pero a la vez perturbados con frecuencia por el temor y la angustia" ${ }^{131}$. Anuncio que solo es posible si la Iglesia, y la familia que participa de ese anuncio, es comunidad de creyentes, comunidad de esperanza vivida y comunicada, comunidad de amor fraterno, necesitada de escuchar sin cesar lo que debe creer, las razones para esperar, el mandamiento nuevo del amor ${ }^{132}$.

La familia concretamente evangeliza por medio de su servicio educativo. Sobre esto, el número $39 \mathrm{~b}$ de la $\mathrm{FC}$, recogiendo las palabras del Concilio en su declaración sobre la educación cristiana, afirma que el cometido de la educación en la familia es fundamentalmente en la fe y la esperanza como motor de la madurez en la persona y las virtudes sociales.

El contenido de la educación cristiana no persigue solamente la madurez propia de la persona humana [...] sino que busca, sobre todo, que los bautizados se hagan más conscientes cada día del don recibido de la fe, mientras se inician gradualmente en el conocimiento del misterio de la salvación; aprendan a adorar a Dios Padre en espíritu y en verdad (cf. Jn 4:23), ante todo en la acción litúrgica, formándose para vivir según el hombre nuevo en justicia y santidad de verdad (Ef. 4:22-24), y lleguen al hombre perfecto, en la edad de la plenitud de Cristo (cf. Ef. 4:I3), y contribuyan al crecimiento del Cuerpo místico. Conscientes, además, de su vocación, 
acostúmbrense a dar testimonio de la esperanza que hay en ellos (cf. I Pe 3:I5) y a ayudar a la configuración cristiana del mundo [... $]^{133}$.

Más adelante, en el número 3 de la GE se hace también explícita la referencia a la educación en el amor, invitando a los padres a crear un ambiente de amor y de piedad hacia Dios y hacia los hombres, que favorezca a la educación íntegra personal y social de los hijos.

En otros apartados, la FC se refiere a la familia con la vocación de ser testigo de la alianza pascual de Cristo mediante la constante irradiación de la alegría del amor y de la certeza de la esperanza, de la que debe dar razón ${ }^{134}$, ya que la luz del Evangelio brilla en la vida familiar cuando los hijos de la promesa, fuertes en la esperanza y en la fe, aprovechan el tiempo presente ${ }^{\mathrm{I} 35} \mathrm{y}$ esperan con paciencia la gloria futura $^{136}$. Proclama en voz alta tanto las presentes virtudes del reino de Dios como la esperanza de la vida bienaventurada ${ }^{137}$.

La familia es el lugar de la verdadera esperanza porque en ella se da la posibilidad de aprender y experimentar lo que el papa llamaba los lugares de aprendizaje y ejercicio de la esperanza. Ella es el lugar en el que se aprende a orar, a vivir, a sufrir y a experimentar el amor misericordioso de Dios que perdona y acoge el pecador.

Sobre la vivencia del amor, de la oración y el sufrimiento, a lo que hemos aludido en el apartado anterior, baste decir aquí, que el magisterio enfatiza la importancia de la oración en el seno de la familia ${ }^{138}$. La oración no puede descuidarse jamás, ya que ella es fuente de luz, de fuerza y alimento de la esperanza cristiana ${ }^{139}$. La familia vivencia el fondo de su más íntima verdad si ella descubre que la "buena nueva" conoce el lenguaje de la cruz, del sufrimiento, de las adversidades. Ser fieles en los momentos difíciles es el mayor testimonio de las familias para el mundo ${ }^{\mathrm{I} 4 \mathrm{O}}$.

\footnotetext{
I33 GE 2.

134 Cf. FC $52 \mathrm{~d}$.

135 Cf. Ef. 5:I6; Col 4:5.

I36 Cf. Rom. 5:25. Cf. LG 35 b.

$137 \mathrm{LG} 35 \mathrm{c}$.

I38 Cf. FC 6f y 60 a.

$139 \mathrm{Cf}$. FC $77 \mathrm{~h}$.

I40 Cf. FC 86 k.
} 
De allí que a la familia, al vivir en la gran esperanza que ilumina las pequeñas esperanzas, le corresponde una educación en la realidad de la existencia. La tentación de la cultura actual es evitar a toda costa cualquier indicio de dolor o sufrimiento, ocultándolo o mostrando la realidad como o un "jardín de rosas" o por el contrario, como un "lugar de maldad" del cual hay que esconderse.

La educación en la realidad pasa por presentar "la concreta vida humana" en todas sus dimensiones de alegría y de tristeza, en las que hay momentos de profunda alegría y de profundo dolor que sobrevienen sin esperarlo, por una razón: la vida es así y no hay otra. Karl Rahner expresaba que la auténtica tarea total y envolvente del cristiano como cristiano es la de ser un hombre... la vida cristiana es aceptación de la existencia humana en general, pero por una razón fundamental: cree en las promesas del Dios vivo ${ }^{\mathrm{I} 4}$.

Amar, esperar y confiar en Dios significa entonces dejarse amar por él, experimentar que en la casa del Padre. Cristo nos espera y confía en el ser humano aun con sus miserias, absurdos y desaciertos. La vida en amor, esperanza y fe es una vida compartida que nos hace libres. El mismo Rahner se refería a esto cuando expresaba que el cristiano es un hombre y una mujer de esperanza en cuanto es libre. Una libertad que se desprende de la esperanza como apertura a todo, a la verdad absoluta, al amor absoluto, ya que Cristo nos ha redimido para su libertad, este autor lo expresaba así:

Libertad en definitiva no es la ausencia de poderes determinantes de nuestra existencia; hasta cierto punto cabe aspirar a esa libertad, cosa que también es posible y constituye un encargo real al hombre. Mas para nosotros, que nacemos y morimos sin ser consultados, y también sin ser consultados hemos asumido un determinado espacio de vida - a la postre inmutable para nosotros-, no hay una libertad inmediata como ausencia de todo poder que codetermine nuestra existencia. Pero el cristiano cree que a través de este cautiverio mismo hay una puerta hacia la libertad, hacia una libertad que no podemos conseguir a la fuerza, sino que nos

I4I Rahner, Curso fundamental sobre la fe..., 464. 
da Dios, en cuanto él se entrega a sí mismo a través de todos los cautiverios de nuestra existencia ${ }^{\mathrm{I} 42}$.

Es en la realidad humana, entonces, en la que la esperanza cristiana resplandece y para esto la familia, como escuela de esperanza, educa en percibir la realidad con nuevos ojos, ella es instrumento de paz y esperanza si en medio del odio pone amor; si cuando hay ofensas ofrece el perdón; si al decaer la fe pone confianza; si en los momentos de desesperación ofrece fortaleza; si en las tinieblas y en la tristeza del mundo mantiene la llama de la luz y la alegría que da el estar sobrecogidos con la gran Esperanza. 